Acta Poetica 24

2003

\title{
Anne Ubersfeld
}

\section{El habla solitaria}

La doctora Anne Ubersfeld, una de las figuras más notables dentro del campo de la semiología teatral, es autora de obras tan cruciales para los estudios dramatológicos como Lire le théâtre (Éd. Sociales, 1978), L'école du spectateur (Éd. Sociales, 1981), Le dialogue de théâtre (Belin, 1996), Les termes de l'analyse du théâtre (Seuil, 1996), entre muchas otras. Su trabajo teórico y crítico ha abierto todo un horizonte de investigación sobre el arte escénico, gracias a su consideración de características específicas del fenómeno teatral, tales como el espacio de representación, las dinámicas entre actores y espectadores, y las peculiaridades estéticas de la concepción, montaje y recepción de la ficción dramática.

El presente artículo inédito, fruto de sus recientes reflexiones sobre el teatro contemporáneo de distintos autores franceses, en relación a nuevos usos de la palabra en escena, nos fue amablemente entregado por la doctora Ubersfeld como colaboración especial para este número de Acta Poetica. 
A partir de Beckett, caímos en la cuenta de que el habla teatral podía echar a andar sus espirales y laberintos en total ausencia de respuesta, de diálogo.

La razón de esta evolución (si no es que revolución) no oculta misterio alguno. Se remite a dos fenómenos. En primer lugar el vínculo con la realidad, una realidad que en el mundo occidental ha limitado singularmente las oportunidades de interlocución ("al metro, a la chamba y a la cama"), tanto en el orden de lo cotidiano como en el seno del trabajo e incluso en el ocio (la televisión). En segundo lugar, sorprende el sentido de la revolución teatral que, a partir de Artaud, privilegia la relación directa del cuerpo con el espectador. Si bien el teatro no es el cuerpo por sí mismo, sino el cuerpo parlante, cuando el habla ya no está empeñada en un intercambio, todo el trabajo escénico corresponde al cuerpo del actor. Toda gloria y toda expresión le pertenecen: postura física tanto como posición social, igual que emociones afectivas. El habla solitaria es el sitio del actor: cuerpo y voz, mímica y dicción.

Vayamos más allá. Bien sabemos que en el teatro hay que avenirse con una contradicción fundamental: el habla siempre está dirigida al espectador/ el habla nunca está dirigida al espectador. Ahora, al actor le corresponde mostrar/resolver esa contradicción, más poderosa en la medida en que él no tiene un otro a quien dirigirle la palabra. En cuanto al contenido del habla, al actor le corresponde mostrar a cada paso lo que es el acto de habla fundamental; dicho de otro modo, mostrar a cada instante no solamente lo dicho sino lo hecho por la palabra.

\section{Una evolución}

1.- Parecería que hubiéramos pasado del teatro naturalista burgués a un teatro de estructura afín en el que el habla de las ca- 
pas populares se hace oír. Es el teatro de lo cotidiano (Kroetz, Deutsch), donde la interlocución popular reemplaza a la interlocución burguesa. Pero lo primero que escuchamos, y que resulta novedoso, es una dificultad de comunicación.

2.- Se escucha un nuevo funcionamiento del habla, que Beckett exhibe: el habla se ha vuelto un habla autónoma más o menos desprendida de la comunicación, o un habla que comunica de otro modo. Es lo que muestran obras nuevas como las de Vinaver, que son invenciones dentro del funcionamiento del habla teatral.

3.- En obras más recientes aparece un uso nuevo del habla atrapada en una no-funcionalidad comunicativa.

\section{Louis Calaferte}

Singularmente, Louis Calaferte propone en su excelente pieza (quizá la mejor de todas) Un riche, trois pauvres [Un rico, tres pobres] todas las maneras en que la palabra humana puede expresarse sin comunicar. Él lo señala: intenta una provocación a la generalidad del empleo del lenguaje "para tantos personajes como uno quiera (o pueda) [...] en cualquier lugar del vasto mundo". Por principio, el silencio de la pareja de 40 años que se halla frente a frente, y que termina sólo por gritar: "Buaaah"; luego, el silencio del hombre apasionado frente a su maniquí al que desviste y luego desgarra, imagen parlante de una incomunicación mortífera. La necesidad de comunicación como deseo patético: la mujer que grita "¡mamá!” en todos los tonos, y el hombre excluido que lleva un letrero escrito: "Sólo pido que me hablen", y la transeúnte que suplica a los demás transeúntes: "regálenme un minuto... sólo un minutito [...], es muy importante", mientras que la multitud "circula glacialmente indiferente". Hacia el final, hay "desplazamientos rápidos e incesantes de personajes en todos los sentidos" y cada uno lanza 
al azar diferentes entonaciones de una sola palabra: Yo [MOI]. Cuando el diálogo existe, se presenta como incomunicación, como mera comprobación de evidencias, por ejemplo entre esos testigos de un accidente que comentan sobre el hecho de "tener cuidado", o la mujer que se queja sobre el destino del mundo, a quien un transeúnte le responde: "A mí me tiene sin cuidado, yo ya estoy más allá", o los dos señores que intercambian atroces lugares comunes en torno al "bonito clima", cuando no recaen en la vacía interlocución de las más redundantes cortesías. Dos niños repiten el diálogo de horrores sostenido por sus padres. Y lo peor, las ofensas consumadas por el Director en contra de Mouchel, quien le responde siempre: "Sí, señor director."

-Mouchel, a partir de este momento lo llamaré pendejo, simplemente pendejo.

—Sí, señor director.

Es el momento en el que el diálogo no conlleva ya comunicación alguna, sino la pura evidencia de una relación de fuerzas. Tal como cuando el Profesor exclama: "iQue nadie toque eso! ¡Es mío!” Ejemplos provocadores y caricaturescos, pero que exhiben las nuevas relaciones entre el habla y el mundo, los nuevos intercambios. ¿O más bien una ausencia de intercambios? Y el teatro es el lugar donde se muestra este nuevo empleo del habla.

Esta singular crítica de las relaciones de habla entre los hombres al final del siglo xx y principios del XxI ha aparecido bajo las formas menos directas, menos abiertamente satíricas en buen número de obras teatrales francesas a lo largo de los últimos veinte años; en las mejores, que van de Vinaver a Durringer.

No hay que confundirse: este nuevo uso del lenguaje no es (por lo general) lo que puede llamarse soliloquio según la fórmula de Bajtín: "El soliloquio se define como una actitud dialógica respecto de uno mismo. Es una conversación en la 
que uno es su propio interlocutor" (La poética de Dostoievski). En este caso no se trata ya de un auto-diálogo sino de un habla sin efecto de intercambio, que es algo muy diferente. El otro no es el yo con sus problemas y contradicciones, el otro es verdaderamente el Otro, de quien no se tiene conocimiento, con quien no se puede establecer comunicación.

\section{Vinaver y el contrapunto}

Yendo más lejos que Beckett, sin duda Vinaver fue el primero que intentó montar el lenguaje en su estado de dispersión, adquiriendo sentido no a partir de la interlocución y de la enunciación en dirección del alocutario, sino a través de lo que el espectador construye a partir de la combinatoria de las réplicas. Así ocurre en la extraordinaria Demande d'emploi [Solicitud de empleo] en donde se conjugan las réplicas, casi siempre breves, que conciernen al futuro de la muchacha - embarazada, y que no quiere abortar-, y el diálogo entre el padre - candidato a un empleo- y su futuro empleador. Así, en el siguiente ejemplo (la madre, Louise, acaba de conseguir trabajo):

Louise.- ¡Funcionó, querido!

Wallace.-Tenemos proyectos por todas partes.

Nathalie.- ¡Ay, papá! ¡Estoy súper, súper contenta!

En un diálogo que sólo lo es imaginariamente, se hallan en conjunción la relación impetuosa de la hija a la vez con el padre y con su futuro hijo, la satisfacción casi provocadora de la madre que salva las finanzas de la familia y el tono impersonal del futuro empleador. Por una especie de paradoja, las relaciones del locutor a la vez con su ego y con el otro están fuertemente indicadas, en tanto que nos hallamos en la situación teatral de incomunicación.

Lo notable es que aquí la incomunicación es sólo aparente, justamente "teatral"; lo que se expone no es un bloqueo de la comunicación sino sus dificultades contingentes, "históricas" 
si así puede decirse, y que Vinaver materializa con el estallido del discurso mediante un trabajo de contrapunto. Esto le permite una aproximación a la vez "moderna" y profunda de las diversas facetas del comportamiento humano, mientras que la conciliación no realista, no racional de las réplicas hace surgir relaciones alternas, riquísimas tanto desde el punto de vista histórico (o ideológico) como desde el puramente psicológico. La yuxtaposición de lo incongruente funciona como una metáfora de carácter poético. Paradójicamente, permite la construcción de personajes comprendidos al mismo tiempo en su individualidad y en sus relaciones.

De esta manera, las últimas interlocuciones-sin-interlocución en Nina, c'est autre chose [Nina es otro asunto]. Puesto que ella estaba de más en la pareja fraternal, la mujer que ha sido amante de uno de los hermanos y lo ha abandonado sin ningún drama, viene a decir adiós acompañada de su nueva amante. Los hermanos le ofrecen a la novel pareja el paquete de dátiles que acaban de recibir. Esto trae a cuento a la mujer bereber que encontraron cierta noche:

Sebastien.- Llevaba unas campanitas colgando de su brazalete y sus collares.

Nina.- Se deshacen en la boca.

Charles.- A nosotros no nos gustan mucho mucho que digamos.

Sebastien.- Bueno, si a ustedes les gustan puedes llevártelos.

Podríamos ir más lejos, más allá en este desencuentro de parejas, mostrar la yuxtaposición de las réplicas en la que los locutores no tienen nada que decirse, y simplemente hablan en el mismo espacio. Estado máximo de la incomunicación, en el que se plantea al espectador la presencia en común de unos seres cuyo lenguaje manifiesta cierto estado, y que le "hablan" exclusivamente a través de esa presencia en común. Ahí lo esencial del trabajo será confiado a la puesta en escena y al desempeño de los actores. 


\section{Philippe Minyana}

Uno de los más brillantes autores dramáticos actuales, Philippe Minyana, escribe aprovechando esta inquietud: hay que exhibir las nuevas relaciones lingüísticas que se suscitan entre nuestros contemporáneos. No nuevas, más bien particularmente significativas de la situación de las relaciones humanas. Uno de sus primeros textos, Fin d'été à Baccarat [El fin de verano en Baccarat], se construye mediante una simple yuxtaposición de seres en un lugar de veraneo; seres humanos no distantes entre sí por razones de diferencias de clase social, origen o cultura, pues se trata mayoritariamente de profesores que vacacionan; más bien su imposibilidad de relacionarse se hace sensible en la medida en que cada uno (con su pareja) aporta sus propias dificultades interiores de comunicación, al tiempo que se muestra la imposibilidad de construir nuevas relaciones mediante el intercambio oral.

Por ejemplo: cuando todos los pensionistas han salido a dar un paseo, uno de ellos, el único que permaneció en el hotel y no se unió al grupo, en el cual se encuentra su compañera Agathe, aparentemente le ha hecho el amor a la guapa recamarera. Hay un esfuerzo extraordinario por presentar las relaciones humanas con ayuda de intercambios lingüísticos muy limitados. Ni siquiera las tentativas por cambiar de pareja desembocan en una verdadera interlocución. El único personaje que logra realizar actos de habla eficaces es la dueña del hotel, en la medida en que sostiene relaciones "económicas" con el mundo y con los demás.

Lo característico del Minyana escritor de teatro es su uso del monólogo. Por medio de él, conduce la construcción de un personaje que no solamente dice yo [je], sino que intenta salvar algo mediante la construcción de ese yo [moi] (no sin conflictos internos). El monólogo tradicional es un acto de reivin-

dicación establecido no ante un ser sino ante el mundo, el 
conjunto de lo social. En cambio, el de Minyana, modelo del monólogo contemporáneo, no es ya más la deliberación de un ser presa de su problema, que pasea su ego a través de diversas posibilidades que se le ofrecen, que juega con las inquietudes de su sensibilidad, ensayando mediante la imaginación todos los actos posibles que han de conformar su futuro. El monólogo de Minyana es el relato de un ser que considera su pasado y las etapas que lo han llevado a ser así, ante un juez virtual o real: como Arlette la infanticida, víctima de traiciones masculinas sucesivas, que le habla a cierto Kiki quien le ha obsequiado gladiolas, pero de quien no sabremos nada más.

En cada uno de los monólogos que componen Chambres [Recámaras], quizá el mejor de los textos de Minyana, lo que se enuncia son las etapas de un ego que rehace su trayecto manteniendo como contrapunto la perspectiva inmediata. Por ejemplo, para Elizabeth, la elección del atuendo que, según supone, le traerá buena suerte. En su discurso se mezclan tres elementos: el ensueño muy concreto, la elección presente entre sus dos amantes, y el pasado, la angustia por la madre. Pero el elemento central es siempre el regreso atrás, el trabajo de la memoria que produce en el discurso los momentos poéticos. Ahí se muestra cómo se conjugan, en la escritura, el trabajo de lo concreto que establece el vínculo entre la actividad psíquica del personaje y el mundo, y el trabajo propiamente poético de la sintaxis enumerativa.

De manera muy perversa, pero muy apasionante, Minyana produce otro modelo de habla solitaria: por una especie de paradoja, la palabra a través de la radio o la televisión mueve a estos personajes a contar su historia. Como en el texto Inventaires [Inventarios], en el que tres mujeres cuentan su vida en un programa televisado bajo la conducción de una animadora. En él, la confesión se somete no sólo a la contingencia de la palabra, sino a su fragmentación. Interviene entretanto otro elemento, el deseo de sacar provecho individualmente ante un 
público; algo que va más allá de una autojustificación como la que se producía en Chambres. Surge ahora un habla un tanto cuanto diferente; surge ahí la relación de cada una de las mujeres entrevistadas con un objeto clave de su vida. ¿Se trata quizá de un artificio excesivo? En absoluto. Es una forma particularmente elocuente de teatro dentro del teatro: cierta "verdad" nos es comunicada mediante el simple empleo de la percepción segunda.

Otra obra, también apasionante y dentro de la misma perspectiva del habla solitaria - y también del teatro dentro del teatro-, es Anne-Marie [Ana María], en donde lo que se escucha y lo que se ve es a un grupo de vecinos, sin verdaderos vínculos entre sí, que intercambian expresiones acerca de un espectáculo invisible para el espectador, que ocurre dentro de la casa de un vecino donde aparentemente una familia tortura a la abuela. En este caso, los intercambios no son, ni mucho menos, personales; son intercambios de espectadores puros - espectadores frente a los espectadores de teatro. De nuevo se suscita aquí el habla no comunicante, o que comunica no más allá de lo que todo el mundo sabe, que comunica sólo para los demás vecinos espectadores o que podrían serlo, que no dicen nada más que el espectáculo al que asisten, en el que participan a través de la mirada: forma perversa de teatro dentro del teatro.

El trabajo de Minyana consiste, pues, en provocar un habla sin ningún deseo de interlocución, un habla que se contenta con liberar la(s) carga(s) que sobrelleva el ego ante un auditorio anónimo - incluso ausente-, una especie de liberación abstracta que no espera respuesta alguna, o en todo caso sólo la respuesta virtual de una colectividad sin rostro. Es un recurso que responde al uso perverso del habla en los medios de comunicación, la radio y sobre todo la televisión. Una manera sagaz de tomar lo propio de la televisión y anexarlo al teatro. De ahí la satisfacción del espectador, no privada de angustia, 
como si de golpe se le expusiera una soledad desesperada para la cual el habla-confesión fuera sólo una curación provisional. Habla que es al mismo tiempo un relato novelesco en el que se hallan exhibidas las etapas por las que el ego de los personajes ha pasado hasta llegar a su estado actual —reflexión sobre una historia, como en la asombrosa André [Andrés], donde el personaje de la narradora relata justamente un intercambio, un intercambio mudo en el seno de una pareja, hasta el suicidio final del marido y la fórmula final de la narradora: “PPor suerte tengo mis campos, mis prados! ¡Allá, allá y aún más lejos! Al mirar esos campos y prados me digo: son mis campos y prados, y dejo de llorar".

\section{Durringer}

Muy diferente es la tentativa de Durringer, el más "actual" — si cabe decirlo así- de los autores contemporáneos de teatro. Consiste en un intento de mostrar el uso concreto del habla entre los jóvenes, un uso que es comunicativo mas en circunstancias y mediante procesos muy originales; un habla que parece ser a la vez "realista" (aunque muy diferente a la del teatro de lo cotidiano) e inventada. Lo verdaderamente interesante es esa invención de un habla activa en la medida en que es expresión de un impulso tenaz, pasional. Así en Une envie de tuer sur le bord de la langue [Un deseo de matar en la punta de la lengua], donde aparecen unos seres reunidos por el azar en un lugar indeterminado, de noche, cerca de una discoteca: son una pareja a punto de romper, una muchacha y su hermano - un joven Don Juan de barrio-, y un oyente casual mayor que ellos, que escucha los discursos pasionales: pasión de Jean por su mujer que lo quiere abandonar, y del joven Muñeco por su hermana, que dirigen sus discursos al testigo. Invención de la forma característica del teatro contemporáneo, el relato re- 
ferido, una forma clave que puede derivarse en los modos más diversos: es el cuasi-monólogo, la recuperación moderna del monólogo clásico (y romántico, que se extiende hasta la época contemporánea). El cuasi-monólogo es una posibilidad de la expresión de yo [moi] dirigida a quien no puede o no quiere responder. Es la recuperación contemporánea del antiguo discurso pronunciado no ante un interlocutor sino ante el coro. La diferencia es que el coro a veces responde, mientras que la situación del hablante contemporáneo es ejercer la palabra frente a un no hablante, aunque es una palabra dirigida a un ser y que en algún momento formula una pregunta. En Chronique des jours entiers [Crónica de los días enteros], es una paradoja: la interlocución se pervierte como si cada uno dijera al otro lo que éste no puede comprender, como la muchacha que dice a su amante que lo ama justamente porque él no es nada y no tiene nada.

En Durringer, la paradoja mayor se encuentra en su último texto, La Promise [La prometida], en el que por una especie de inversión el habla cuasi-monológica es la de un fantasma, el del hombre que violó en la guerra a una joven que procreó un hijo y fue repudiada por su familia. El fantasma se le aparece a la víctima y se expresa en los términos de una moral religiosa casi universal: como si ese habla diera forma a la conciencia de la víctima. Ahí, el trabajo del habla sin interlocución se convierte en el habla de lo trágico: la joven solitaria y abandonada repite las palabras del espectro, palabras de una esperanza desgarradora.

\section{Jean-Luc Lagarce y la escritura novelesca}

Lo que apreciamos en el escritor prematuramente muerto JeanLuc Lagarce, es un singular trabajo de desprendimiento de la réplica. Incluso cuando ésta se dirige a alguien, al propio tiempo se aleja de su destinatario por ausencia de comunicación con- 
creta. La réplica está adecuadamente destinada, no al vacío, sino a fulano o zutano. Sin embargo, este otro al que el yo [je] le habla está fuera de alcance, ya sea porque ha muerto o porque pertenece al pasado definitivamente extinguido: se trata de verdaderas interlocuciones, pero que ocurren en lo imposible. Así, en Le pays lointain [El pueblo lejano] Louis el protagonista regresa a su lugar de origen para encontrarse con su familia (se está muriendo de sida), y dialoga en el mismo plano con el Amante muerto, con el Padre también muerto, con cierto "Antaño", con personajes anónimos, con un Muchacho, con todos los muchachos, con un Guerrero, con todos los guerreros. En su familia (madre, hermano y hermana), hay una cuñada a quien no conoce. El todo de la obra consiste en una extraordinaria mezcla, una sorprendente "fábrica", una novela proustiana capaz de reconciliar el presente con el pasado. El regreso del protagonista al seno familiar produce, como en Proust, una especie de estallido físico al que ni el tiempo ni el espacio resisten, en tanto que el cuerpo multiplicado de los habitantes del pasado se vuelve la imagen física del tiempo, del tiempo individual del protagonista (véase la primera página de la obra).

\section{El cuasi-monólogo en Koltès}

El cuasi-monólogo es la forma clave en la obra del más grande dramaturgo contemporáneo. ¿En qué consiste? Se trata de un soliloquio. No es monólogo, porque el discurso se dirige a alguien más. Pero el cuasi-monólogo posee una característica: no obtendrá respuesta; y podría decirse que se enuncia para dar a quien lo escucha (el espectador) la certeza de que no será respondido.

Toda habla es implícitamente una petición: escúchame, haz lo que te pido, etc. En el teatro, toda réplica constituye un acto de habla, ya sea una petición, una pregunta, un reproche o una orden (la lista no se cierra aquí). Esto vale para toda réplica. 
Pero el cuasi-monólogo posee la característica de ser un acto que quedará "en el aire". No tendrá respuesta.

El uso de esta forma clave conduce al teatro de Koltès de la insignificancia al genio. ¿Cuál es su origen? El sentimiento y la idea de la soledad en el cruce de la vida con la filosofía y la escritura... la soledad contemporánea. En palabras de Koltès: "Vivir en pareja... no resuelve el problema. Es un hecho fundamental, todos los hombres... toda la humanidad está completamente sola..., nacemos solos, morimos solos (entrevista con L. Attoun, Théâtre public, núm. 36-37). ¿Hay que negar entonces el amor? Por supuesto que no, pues ahí yace el origen del drama. A la pregunta de Attoun, “¿Y el amor?”, el dramaturgo responde: "Si no existiera, todos no colgaríamos".

En la obra de Koltès, en dos ocasiones el personaje central grita de desesperación. En Dans la solitude des champs de coton [En la soledad de los campos de algodón], la gran réplica del Cliente hacia el desenlace final, que manifestará la muerte, es un quejido: "No hay amor, no hay amor". Y en Roberto Zucco, el protagonista exclama: "Los hombres necesitan a las mujeres, y las mujeres necesitan a los hombres, pero lo que se llama amor, eso no existe". Exclama lo anterior mientras habla por un teléfono mudo que tiene el cable cortado.

Ésta es la estructura fundamental: alguien habla, se queja, suplica, pero nadie le responde. El primer gran texto de Koltès, La Nuit juste avant les forêts [La noche muy adentro del bosque], es un parloteo infinito sin mucha puntuación, una sola oración, un flujo de lenguaje sin que ningún signo procedente del otro venga a desviar el curso del discurso. Un hombre solo habla en una calle, bajo la lluvia. Le habla a otro hombre, un joven, a quien no veremos, pero cuya existencia no parece ser la de un fantasma del hablante: "Diste vuelta en la esquina de la calle, cuando te vi [...] De lejos me di cuenta que eras un niño, una especie de perrito faldero abandonado en la esquina". 
En este parloteo sin límite preciso, hay un solo acto de habla, la petición o demanda que parece no poder contenerse. ¿Qué demanda? No lo sabremos, pues una confusión deliberada impide al espectador restringirse a una sola situación, ya sea la del ligue homosexual o la de la mendicidad. Frente a tal imprecisión, un solo sentimiento, el de la urgencia de la demanda que termina por revestir un aspecto de búsqueda inútil, casi "religiosa" del otro, un anhelo extraviado por salir de ese infierno que es la soledad, materializado por la noche y la lluvia.

¿Y esa búsqueda? Permítasenos aproximarla a lo que Lacan llama la demanda de amor. Se advertirá entretanto un fenómeno que no es novedoso, la aparición coincidente de obras nuevas y de una teoría que las alumbra. ¿La demanda de amor? Para Lacan es ese impulso que, en el adulto, reencuentra lo que fue el lazo primordial del niño con la madre. Una relación dual, no triangular como la que planteara René Girard.

En palabras de Lacan: "La demanda de amor es una demanda de amor, una demanda absoluta que simboliza al Otro como tal, que distingue pues al Otro como objeto real capaz de suministrar tal o cual satisfacción, demanda del Otro en cuanto objeto simbólico que da o rechaza la presencia, matriz en la que se cristalizarán las relaciones fundamentales que están en el horizonte de toda demanda, el amor, el odio, la ignorancia”. (Séminaire V). Ahora bien, la demanda de amor es tal que no puede obtener respuesta.

El teatro de Koltès es el repertorio de las mil y una maneras de decir esta búsqueda sin esperanza. Así, en Combat de nègre et de chiens [Pelea de negro con perros], la desesperada demanda de amor de Léone al Negro Alboury: “¡Oh negro, color de todos los sueños, color de mi amor! Te lo juro [...], tu tierra será mi tierra" (XV). La respuesta será gestual. Alboury escupe el rostro de Léone.

En el texto de culto Dans la solitude des champs de coton [En la soledad de los campos de algodón], aparentemente no 
hay cuasi-monólogo, pero cada una de las réplicas se formula de modo tal que no puede obtener respuesta. Así, hasta la última, que no tendrá más que respuesta física. La imprecisión tiene como resultado que la demanda sólo pueda ser comprendida como demanda absoluta de contacto en el otro, como si la oferta comercial fuera forzosamente metáfora de esa demanda. $\mathrm{O}$, dicho con más precisión, se pasa de la demanda de amor a la solicitación del deseo: "dime qué es lo que quieres", donde aparece (de nuevo, Lacan) "el deseo del deseo del otro" (Ibidem). De ahí el pasaje del cuasi-monólogo al diálogo, diálogo hecho de una sucesión de demandas sin respuesta, hasta la aparición del Deseo absoluto, la Muerte.

\section{Yasmina Reza}

Muy diferente es el trabajo de cuasi-monólogo en el teatro de Yasmina Reza, lo que prueba la vitalidad y la riqueza de esta forma, al tiempo que la revela como característica de las formas contemporáneas de escritura teatral.

En su muy bella primera pieza, hay un monólogo que no podría calificarse de cuasi-monólogo: esa llamada al padre muerto no habrá de obtener respuesta, y sin embargo es un llamamiento tan directo, tan vigoroso que no puede ostentar el estatuto del monólogo puro, que consiste en una meditación o discurso dirigido al espectador. Pero hay una particularidad asombrosa y brillante en el texto: dos cuasi-monólogos que ponen fin a la pieza, pronunciados por los dos hermanos rivales, y que constituyen dos llamamientos oníricos, dos llamados a la comprensión, a la reconciliación profunda en torno al nuevo amor y al paso de la mujer de uno a los brazos del otro. Son dos ensoñaciones ante toda la familia, pero visiblemente dirigidas, cada una, a un hermano; un verdadero cuasi-monólogo, donde el efecto perlocutorio emocional es potente: el ensueño de una ruta en común en el preciso momento en que los destinos divergen. 
Su contenido es un regreso al pasado: para uno, al pasado inmediato, vuelto a vivir bajo el aspecto del sueño, de la reconstrucción imaginaria; para el otro, un regreso al pasado lejano, un regreso que reconstruye su vida, no bajo el aspecto de una construcción imaginaria sino de una confesión, es decir de un discurso centrado sobre el yo [je]. De hecho, esta primera persona debe ser matizada: es un nosotros para uno, y un yo [je] para el "abandonado". Hemos dicho "llamamiento", pero no se trata de un llamado explícito; somos los espectadores quienes lo entendemos así, gracias a la misma "actitud de habla" — si así puede decirse - de actos de habla diferentes, que son una reflexión sobre el destino. Ahora bien, esta reflexión sólo puede significar un acuerdo sobre la significación y el futuro de lo que podríamos llamar un destino familiar, establecido con alguna parte de una comunidad. Esta comunidad queda inmediatamente expresada por el hecho (última réplica del cuasi-monólogo) de que todo el mundo va a comer de la "olla" que el locutor va a adornar "con todas las plantas aromáticas vivas de la cocina", y el término vivas no es pronunciado por mero azar.

En cambio, el único cuasi-monólogo en Art [Arte], el único que podríamos designar así pues es un habla pronunciada ante un testigo, y que no recibe respuesta, es de hecho un gran discurso de rencor frente a toda la familia, frente a las dos familias, justo antes del matrimonio; discurso que espera suscitar una compasión que no despierta. Los otros soliloquios son verdaderos monólogos clásicos, que exponen la situación material o psíquica, dirigidos al espectador.

Tres monólogos, para empezar. El primero es el de Marc, a quien no le gusta el cuadro pictórico. Monólogo puramente expositivo, informativo. El segundo es el de Serge, el comprador del cuadro, que nos informa además sobre Marc. Y el tercero es una reflexión, más bien negativa, de Marc acerca de Serge y su cuadro. Luego de esto, el conflicto halla contorno y 
comenzamos a habérnosla con una forma paradójica de cuasimonólogo: Serge sigue monologando y habla de Marc empleando la tercera persona; luego es Marc quien habla dirigiéndose con toda vehemencia a su amigo ausente, aunque está solo. Por último, aparece Yvan quien dirige a los otros dos un gran discurso sobre sus propios asuntos y complicaciones familiares, un discurso sin respuesta. El final de la obra se compone de tres monólogos. El de Yvan, narrativo y por lo mismo esencialmente informativo, sobre las relaciones entre los tres amigos, y sobre sí mismo y sus pesares. El de Serge, informativo también, que da la clave irónica del desenlace favorable de la aventura de los amigos. Y el de Marc, por último, que es un ensueño, una meditación onírica sobre el cuadro. Estos monólogos, paradójicos o no, engendran la forma ineludible de un déficit afectivo, déficit de correspondencias, déficit trágico que se traduce de manera humorística mediante las lágrimas de uno, el cinismo del propietario del cuadro y el ensueño del último, Marc.

\section{Conclusión}

Por principio, el habla solitaria y estallada en Vinaver puede ser la yuxtaposición de búsquedas diferentes en el seno de un mismo personaje, y marcar la desproporción de poner en juego en nuestro mundo disperso los diversos elementos de nuestras identidades individuales. Forma clave, el habla solitaria es un acto. ¿De qué acto se trata? ¿Qué es lo que hace el habla?

Puede ser un acto de reivindicación contra lo social opresivo, un habla de defensa y, en el límite, una autojustificación. Así lo es en el caso de Minyana. En Lagarce, el habla puede intentar el trenzado o la reanudación de los nudos deshechos, afirmar la permanencia del yo [moi] contra lo que en la conciencia representan lo fugitivo, lo ya desaparecido; puede intentar una justificación frente al prójimo: cosa que es también 
una demanda de amor. Yasmina Reza ofrece una conjunción semejante, más limitada aunque más optimista. En Koltès se trata antes que nada de una demanda de amor. Con cierta "desviación", en Durringer aparece como demanda indirecta, inconfesada, que no carece de alguna consecuencia exitosa.

En todos los casos, lo que esta habla solitaria expresa al espectador es el estallido de los lazos y la dificultad de encontrar al otro, la dificultad o imposibilidad de la interlocución mediante el diálogo. Un clamor: ¡No me dejen solo! Quizá el teatro contemporáneo ofrece al público lo que siempre le ha proporcionado: una lección, una advertencia, un despertar.

Traducción de Jaime Moreno Villarreal 